OPEN ACCESS

Edited by:

Sebastian J. Hofer,

University of Graz, Austria

Reviewed by:

Devin Wahl,

Colorado State University,

United States

Oliver Kepp,

Institut National de la Santé et de la

Recherche Médicale

(INSERM), France

${ }^{*}$ Correspondence:

Lina Ma

malina0883@126.com

Specialty section

This article was submitted to

Clinical Nutrition,

a section of the journal

Frontiers in Nutrition

Received: 26 June 2021

Accepted: 10 August 2021

Published: 06 September 2021

Citation:

Liu P, Li Y and Ma L (2021) Caloric

Restriction May Help Delay the Onset

of Frailty and Support Frailty

Management. Front. Nutr. 8:731356.

doi: 10.3389/fnut.2021.731356

\section{Caloric Restriction May Help Delay the Onset of Frailty and Support Frailty Management}

\author{
Pan Liu ${ }^{1}$, Yun $\mathrm{Li}^{1}$ and Lina Ma ${ }^{1,2 *}$ \\ ${ }^{1}$ Department of Geriatrics, Xuanwu Hospital, Capital Medical University, Beijing, China, ${ }^{2}$ National Clinical Research Center for \\ Geriatric Medicine, Beijing, China
}

Frailty is an age-related clinical syndrome that may increase the risk of falls, disability, hospitalization, and death in older adults. Delaying the progression of frailty helps improve the quality of life in older adults. Caloric restriction (CR) may extend lifespan and reduce the risk of age-related diseases. However, few studies have explored the relationship between $\mathrm{CR}$ and frailty. In this review, we focused on the impact of CR on frailty and aimed to identify potential associated mechanisms. Although CR may help prevent frailty, further studies are required to determine the underlying mechanisms and specific CR regimens suitable for use in humans.

Keywords: caloric restriction, frailty, older adults, sarcopenia, lifespan

\section{HIGHLIGHTS}

- Caloric restriction (CR) has antiaging effects and great significance in delaying frailty and sarcopenia.

- Some suggestions about CR for frailty are proposed.

- Further study is needed to determine the mechanisms and detailed CR interventions appropriate for humans.

\section{INTRODUCTION}

Frailty is an age-related clinical geriatric syndrome associated with the decline of multiple physiological systems and increased risk of adverse health outcomes, such as falls, hospitalization, disability, and premature mortality in older adults $(1,2)$. Frailty is receiving increasing research and clinical attention due to the rapid population aging. The prevalence of frailty is estimated in the range of $4-59 \%$ (3). The Fried phenotype (1) and the frailty index (FI) (4) are two widely used methods for frailty assessment. The frailty phenotype includes features, such as unintentional weight loss, poor muscle strength, exhaustion, reduced physical activity, and slow walking speed (1). Interventions that prevent or delay the onset of frailty are required to improve the quality of life among older adults. The previous studies have examined frailty in rodents (5-8) and humans (9).

High-calorie diets are risk factors for obesity and metabolic diseases (10). Caloric restriction (CR) is defined as a reduction in energy intake (typically by $20-40 \%$ of ad libitum consumption) without malnutrition (11). CR has been reported to considerably extend a healthy lifespan and prevent age-related diseases in both animals and humans (11-14). However, the previous studies have mainly focused on the association between $\mathrm{CR}$ and aging, and few studies have explored the relationship between $\mathrm{CR}$ and frailty. This review aimed to summarize the evidence on the impact of CR on frailty and to explore candidate underlying mechanisms. 


\section{CR AND FRAILTY}

In the clinical setting, the FI may be a lifespan biomarker, helping in predicting age-related mortality (15). A previous study has shown that $30 \%$ CR may enhance strength in both oldand middle-aged male mice and improve balance and motor coordination in both old- and middle-aged female mice; these outcomes are closely associated with a delay in the onset of agerelated frailty (16). In addition, a separate study has shown that both middle-aged and old male mice with the CR of $30 \%$ had grip strength greater than that observed in their counterparts (17). Old male C57BL/6 mice that consumed a 40\% CR diet over 13 months period, starting from 6 months of age, and that fed an ad libitum diet combined with 6 months of resveratrol treatment both improved frailty status compared with their counterparts. However, this difference was not observed in female mice (18). In contrast to the C57BL/6 mice, CR did not delay age-related decline in DBA/2 mice. Male DBA/2 mice on a similar CR diet had a higher risk of frailty than did the matched C57BL/6 mice. There was no difference in frailty assessment by FI among both sexes of CR mice (18). The impact of CR regimens on frailty, activity, and memory in male Wister rats was stratified by CR starting point and duration. A CR of $40 \%$ imposed over 6,12 , or 18 months, starting at 6 months of age, improved the general locomotor activity and spatial memory and decreased the age-related frailty. However, the benefits of CR started in late adulthood were unclear; for example, a CR of 3 months starting at the age of 15 and 21 months increased the risk of frailty in old rats (19). Most studies on CR have been conducted in male animals. Further studies in female mice and rats or other species are required.

A 4-year treatment involving 30\% CR beginning in adulthood (3.2 \pm 0.1 years of age) may extend lifespan by $50 \%$ and reduce the risk of age-related diseases in male gray mouse lemurs, without affecting motor and cognitive performance (20). Meanwhile, 30\% CR may extend the health span in rhesus monkeys (21). In the same species, Yamada et al. have shown that long-term 30\% CR started in adulthood may reduce the incidence of frailty by improving weakness, endurance, slowness, and physical activity and extend healthy lifespan in both the sexes (22).

An interleukin-10 knockout (IL-10-/-) mouse model is the genetic model of frailty (8). However, few studies on CR have used this model. Rapamycin, an inhibitor of mammalian target of rapamycin (mTOR), may improve muscle function and prevent frailty in $\mathrm{IL}-10^{-/-}$mice $(23)$. $\mathrm{Cu} / \mathrm{Zn}$ superoxide dismutase knockout mouse (Sod1 $\left.1^{-/}\right)$is another model of frailty, with characteristics similar to those observed in humans with frailty, such as weight loss, weakness, reduced physical activity, and exhaustion (7). The studies have shown that $40 \%$ CR may attenuate age-related loss of muscle mass of Sod $1^{-/}$mice by improving mitochondrial function, reducing oxidative stress damage and cellular senescence, and decreasing IL-6 levels $(24,25)$. Upregulation of SIRT3 and mitochondrial antioxidant manganese superoxide dismutase expression in CR Sod1 $1^{-/-}$mice may help protect against muscle damage (24).

\section{CR and Frailty in Humans}

The Comprehensive Assessment of Long-Term Effects of Reducing Intake of Energy (CALERIE) trial has shown that 6 months of $25 \%$ CR reduced the levels of fasting insulin and body temperature in overweight adults (26). Further studies have shown that extending CR for 2 years may improve chronic inflammation markers, blood pressure, the levels of glucose, and blood lipids, alongside other cardiovascular metabolic indicators in young and middle-aged healthy adults (27), while improving cognitive function in non-obese healthy adults (28). Dora et al. found that this CR regimen reduced oxidative stress in male and female adults, as indicated by the urinary concentration of F2isoprostane (29). Another study indicated that 12 weeks of CR improved cardiometabolic health in sedentary adults with obesity and aged $\geq 65$ years (14). Age-related loss of skeletal muscle quantity and quality is associated with reduced gait speed and overall strength and a high risk of fall and frailty. A previous study has shown that $15-25 \%$ CR may prevent age-related muscle atrophy in humans (30), potentially improving the frailty. Other studies have shown that time-restricted feeding improved the walking speed and quality of life in overweight sedentary older adults (aged $\geq 65$ years) (31). However, the generalizability of these findings requires further research.

\section{CR and Sarcopenia}

Sarcopenia is an age-related syndrome of muscle strength and functional decline that is closely associated with frailty; in fact, it may contribute to physical frailty. CR exerts a protective effect against sarcopenia in both rodents and non-human primates (32-35). A CR of $30 \%$ over 10 weeks may improve skeletal muscle function in male C57BL/6 mice (33). Lifelong 8\% CR prevents age-related disruption of the myofiber membrane environment in male Fischer-344 rats (32). The effects of different durations $(2.5,8.5$, and 18.5 months) of $40 \%$ CR on skeletal muscle may depend on animal strain, sex, and age (36). Vastus lateralis biopsies collected at 6,9 , and 12 years after the treatment that included a 30\% CR diet have shown that CR may prevent the shift in fiber type distribution and delay cellular atrophy in male rhesus monkeys (34).

\section{POSSIBLE MECHANISM OF CR EFFECTS ON FRAILTY}

The mechanisms of CR impact on frailty remain unclear; several target pathways involved in antiaging may be affected, such as the inhibition of insulin-like growth factor-1 (IGF-1) and mTOR signaling, activation of adenosine $5^{\prime}$-monophosphateactivated protein kinase (AMPK) and sirtuins, and promotion of autophagy (Figure 1) (12). Sirtuins are a conserved family of nicotinamide adenine dinucleotide (NAD)-dependent proteins. Silent mating-type information regulation 2 homolog 1 (SIRT1) and other sirtuins may mediate the protective effects of CR (37). SIRT1 activation may extend lifespan through the activation of AMPK, which further inhibits mTOR, promotes lipid catabolism and gluconeogenesis (38). CR may delay cognitive decline in 


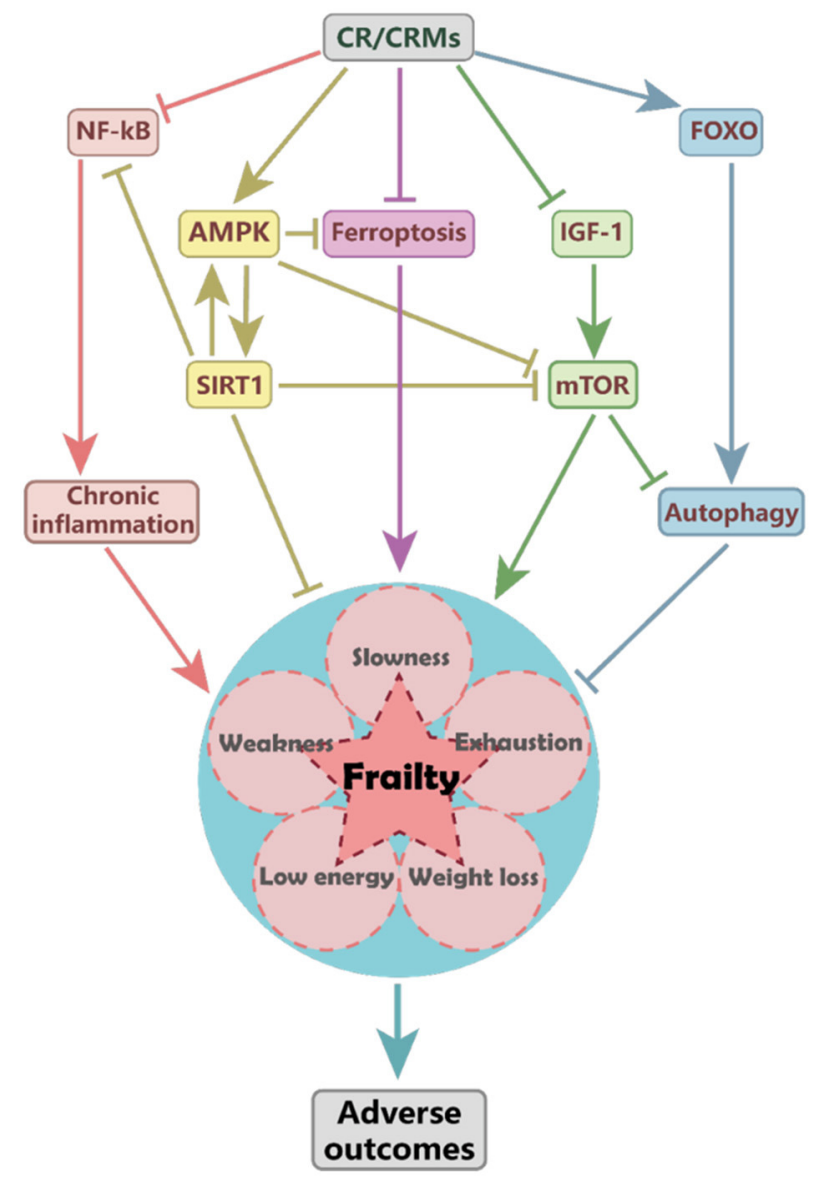

FIGURE 1 | The proposed mechanism of caloric restriction (CR) impacts frailty. CR may reduce the risk of frailty and associated adverse outcomes by activating the AMPK and SIRT1 pathways, inhibiting the IGF-1 and mTOR signaling and ferroptosis, and reducing the inflammation mediated by NF-KB pathways. CR-induced SIRT1 activation may upregulate AMPK and suppress NF- $\mathrm{BB}$ and mTOR activity. CR and metformin may attenuate ferroptosis by activating the AMPK pathway and improving frailty. AMPK, adenosine 5'-monophosphate (AMP)-activated protein kinase; CR, caloric restriction; CRMs, caloric restriction mimetics; FOXO, forkhead box O; IGF-1, insulin-like growth factor-1; mTOR, mammalian target of rapamycin; NF-кB, nuclear factor-кB; SIRT1, silent mating-type information regulation 2 homolog 1.

mice by modulating the SIRT1/mTOR signaling pathway and by activating SIRT1 and suppressing mTOR signaling (39).

Lower sirtuin levels are independently associated with frailty, regardless of age, sex, and comorbidities. Lower circulating levels of SIRT1 and SIRT3 may indicate frailty (40), and frail older adults are more likely than their counterparts to have lower serum-induced SIRT1 expression levels (41). In contrast, the previous study has shown that frail older patients had higher levels of SIRT1 than did their counterparts. Older adults with elevated SIRT1 levels had decreased physical function (42). Nevertheless, serum-induced SIRT1 expression has not been associated with frailty (43). Further studies are required to elucidate the relationship between SIRT1 and frailty and other signaling pathways that may mediate the relationship between CR and frailty.
Cell senescence and chronic inflammation are important characteristics of aging and frailty (44); CR exhibits antisenoinflammatory effects by suppressing the expression of cytokines and chemokines in the senescence-associated secretory phenotype. The CR mimetics (CRMs) may improve the dysregulated activity of signaling pathway molecules (45). A CR diet may delay the onset of frailty and improve the progression of several chronic diseases by reducing the development of chronic low-grade inflammation (46), associated with elevated levels of C-reactive protein, IL-1 $\beta$, IL-6, and tumor necrosis factor- $\alpha$ (TNF- $\alpha)$ (47). Moreover, CR exhibits considerable antiinflammatory activity by modulating the activity of nuclear factor- $\kappa \mathrm{B}(\mathrm{NF}-\kappa \mathrm{B})$ and forkhead box O (FOXO) (48). Activation of SIRT1 may suppress the NF-кB pathway (49). Immune senescence is a natural consequence of aging that is associated with frailty. CR may attenuate age-related changes of the natural killer cells and $\mathrm{T}$ cells to preserve immune function in later life, which is a system-wide effect (50).

Iron dyshomeostasis and ferroptosis may trigger cell and organismal death in Caenorhabditis elegans (51). CR and metformin attenuate ferroptosis by activating the AMPK pathway, which has been associated with extended lifespan and health span and improved frailty (51). CR may protect against cognitive function decline by inducing senescence-accelerated prone eight astrocytes protective gene expression and functional rejuvenation in vitro (52). In addition, CR may improve insulin sensitivity (11) by mediating the adipose mTOR2 pathway; however, the activity of this pathway is not necessary for the beneficial effects of CR (53).

Age-related apoptosis in skeletal myocytes may lead to sarcopenia, which involves mitochondria- and TNF- $\alpha$-mediated pathways (54). Interventions targeting myonuclear apoptosis improve sarcopenia and physical frailty symptoms (55). Lifelong $8 \% \mathrm{CR}$ has been shown to reduce age-related rates of apoptosis and oxidative damage to the skeletal myocyte by regulating autophagy in rats (56). This mechanism may be associated with heat shock protein 27 signaling, which, when insufficient, may contribute to apoptosis and muscle wasting (57). The upregulation of the IGF1-Akt-mTOR-FOXO signaling pathway may accelerate sarcopenia in aged mice (58). CR may help preserve muscle mass in middle-aged rats by downregulating mTOR and ubiquitin-proteasome pathway signaling (59). Further, CR may delay skeletal muscle aging in rhesus monkeys by inducing metabolic changes (60). These findings indicate that CR may delay sarcopenia by reducing oxidative stress damage, inflammation, and iron overload, as well as improving mitochondrial function, enhancing protein homeostasis, and increasing autophagy and apoptosis (61).

\section{TYPES OF CR}

Caloric restriction has been reported to extend health span and lifespan and prevent age-related diseases and frailty. However, the optimum timing of CR initiation or duration remains unclear as few previous studies have focused specifically on frailty. Further studies are required to establish regimens most likely to improve the quality of life of older adults. At the time of writing, several types of $\mathrm{CR}$ regimens exist. For example, the Mediterranean 
CR diet has been shown to decelerate age-related cognitive decline (62) and the progression of aging and prevent frailty (63), making this approach useful for frailty management in the clinical context (64). The clinical impact of CR may depend on the factors, such as compliance; herein, we describe candidate approaches to CR that include intermittent fasting, CRMs, and protein dietary restriction.

\section{Intermittent Fasting}

No diet regimen is suitable for everyone. Different from continuous $\mathrm{CR}$, intermittent fasting consists of periods of little or no energy intake and intervening periods of normal food intake (65), which have benefits for weight loss, healthy aging, and chronic disease prevention (66), such as improving cardiometabolic health in overweight and obese individuals (67). In addition, intermittent fasting may play an important role in reducing oxidative stress, improving insulin sensitivity, repairing autophagy, and improving cognitive function (65). Established intermittent fasting regimens determined by the interval length of fasting $(66,68)$ include time-restricted feeding, alternate-day fasting, alternate-day modified fasting, and the 5:2 diet. For example, the 5:2 diet involved 2 days of fasting with no more than $25 \%$ energy intake and 5 days of regular eating patterns per week (67). Time-restricted feeding may help protect cardiometabolic health; in contrast to $\mathrm{CR}$, it may also be associated with satisfactory compliance as time is relatively easy to monitor (69). In later life, intermittent fasting on alternate days may increase renal gasotransmitter hydrogen sulfide production, which may help reduce age-related frailty in male mice (70).

\section{CR Mimetics}

Caloric restriction mimetics are compounds that mimic physiological and metabolic CR effects (71), such as resveratrol, rapamycin, metformin, NAD precursors, and senolytics (15). They have positive effects on the rodent lifespan and human health and are used in interventions against aging and age-related cardiovascular, neurodegenerative, and malignant diseases (72). Moreover, these compounds may help prevent age-related frailty, as assessed using the FI in mice (15). Several CRMs have been shown to prevent frailty (Table 1); for example, 6 months of resveratrol treatment $(100 \mathrm{mg} / \mathrm{kg} /$ day $)$ starting at 18 months of age has been shown to prevent frailty in mice (18). In addition, 6-week resveratrol treatment $(150 \mathrm{mg} / \mathrm{kg} / \mathrm{d})$ has been shown to improve the grip strength and muscle mass in aged rats through the activation of the AMPK/SIRT1 pathway (73). SRT1720, another SIRT1 activator, may extend lifespan and improve the health of mice through SIRT1 activation and NF- $\kappa$ B expression reduction (74). Frailty is associated with SIRT1 activity in older adults (42); targeting this pathway with CRMs, such as resveratrol may affect both robustness and frailty in humans (37); Metformin has been reported to extend the lifespan of older adults with type 2 diabetes by preventing frailty (75). Exposure to any dose or frequency of metformin administration may reduce the risk of frailty in older adults (76). An 18-month intervention involving rapamycin $(1.5 \mathrm{mg} / \mathrm{kg} / \mathrm{d})$ for $\mathrm{IL}-10^{-/-}$ mice has been shown to prevent muscle mass loss and frailty by decreasing myostatin levels (23). Meanwhile, 12-week treatment with low-dose oral rapamycin $(0.5,1$, and $2 \mathrm{mg})$ failed to improve the frailty status in older adults with coronary artery diseases (77). The combination of dasatinib $(5 \mathrm{mg} / \mathrm{kg})$ and quercetin $(50$ $\mathrm{mg} / \mathrm{kg}$ ), as one of the senolytics, may extend health span and alleviate symptoms of frailty in aged mice (78). In addition, a chronic nicotinamide diet, an NAD + precursor, at doses in the range of 0.5 or $1.0 \mathrm{~g} / \mathrm{kg}$, can improve the health span but not the lifespan of adult mice (79). Future studies are required to elucidate the effects of CRMs on frailty.

\section{Protein Diet}

Macronutrient balance is important for healthy aging. Higher protein intake has been associated with worse frailty status over time in a relatively healthy population; no similar effect has been identified for either carbohydrates or fats (80). Further, low-protein high-carbohydrate diets may help expand lifespan (81). Protein restriction has been shown to affect the rodent lifespan in a manner similar to that associated with CR $(81,82)$. Amino acids, particularly branched-chain amino acids (BCAAs), such as leucine, isoleucine, and valine, are associated with improved health and increased lifespan in different organisms $(83,84)$. Protein restriction may increase the risk of frailty and sarcopenia (85). Intake of a BCAA-enriched balanced amino acid mixture may help preserve muscle fiber quantity, improve motor coordination and endurance, and extend the lifespan of middle-aged mice by modulating the mTOR/eNOS pathway, which affects mitochondrial biogenesis (84). In addition, a BCAA-enriched diet may help prevent disability and extend a healthy lifespan in older adults (86), suggesting that this diet may be suitable for older adults at risk of frailty. In contrast, Richardson et al. suggested that lifelong restriction of dietary BCAAs may extend lifespan and prevent frailty in aged male mice. Nonetheless, the effect of the BCAA diet on frailty remains unclear (87). Further studies are needed to examine these associations in humans. The controversies regarding the effects of BCAA dietary restriction or enrichment may be associated with different factors, such as intervention onset, duration, and species. Further studies are required to elucidate the relationship between protein intake, lifespan, and age-related diseases.

\section{COMBINATION OF CR AND EXERCISE}

Diet and exercise are critical components of healthy aging. Protein supplementation alone may not alleviate sarcopenic symptoms (30). Protein supplementation combined with resistance training is recommended to prevent sarcopenia and frailty (64). The previous studies have shown that a combination of resistance training and $\mathrm{CR}$ for 6 months may improve maximal strength in menopausal women with obesity (88). Meanwhile, other studies have shown that CR combined with resistance training may prevent $\mathrm{CR}$-induced muscle loss in older adults with obesity (89). A separate study has shown that the interventions involving $\mathrm{CR}$ and exercise may improve age-related conditions in adults with type 2 diabetes (90). Thus, exercise may be considered as another type of CRMs, helping prevent frailty and improve healthy aging alone or in combination with CR (91). These effects are likely mediated by antioxidant-related mechanisms (91). However, it should be noted that the combination of $\mathrm{CR}$ and aerobic exercise training 
TABLE 1 | Caloric restriction mimetics and frailty assessments.

\begin{tabular}{|c|c|c|c|c|c|c|}
\hline CRMs & Category & Species & Onset & $\begin{array}{l}\text { Dose and } \\
\text { duration }\end{array}$ & Frailty assessment & Results \\
\hline \multirow[t]{2}{*}{ Resveratrol } & $\begin{array}{l}\text { SIRT1 } \\
\text { activator }\end{array}$ & Male, C57BL/6J mice & 18 months & $\begin{array}{l}100 \mathrm{mg} / \mathrm{kg} / \mathrm{d} \\
6 \text { months }\end{array}$ & Mouse FI & Reduces FI scores (18) \\
\hline & & Male, SD rats & 24 months & $\begin{array}{l}150 \mathrm{mg} / \mathrm{kg} / \mathrm{d} \\
6 \text { weeks }\end{array}$ & Physical function & $\begin{array}{l}\text { Improves grip strength and } \\
\text { muscle mass (73) }\end{array}$ \\
\hline SRT1720 & $\begin{array}{l}\text { SIRT1 } \\
\text { activator }\end{array}$ & $\begin{array}{l}\text { Male } \\
\text { C57BL/6J mice }\end{array}$ & 7 months & $\begin{array}{l}100 \mathrm{mg} / \mathrm{kg} / \mathrm{d} \\
\text { Natural death }\end{array}$ & - & $\begin{array}{l}\text { Extends lifespan and improves } \\
\text { health in mice (74) }\end{array}$ \\
\hline Metformin & $\begin{array}{l}\text { AMPK } \\
\text { activator }\end{array}$ & $\begin{array}{l}\text { Adults aged } \geq 65 \text { years } \\
\text { with type } 2 \text { diabetes }\end{array}$ & $\begin{array}{l}\text { Receiving metformin in } \\
\text { outpatient care }\end{array}$ & - & $\mathrm{Fl}$ & $\begin{array}{l}\text { Reduces risk of frailty regardless } \\
\text { of dose and frequency (76) }\end{array}$ \\
\hline Rapamycin & $\begin{array}{l}\text { mTOR } \\
\text { inhibitor }\end{array}$ & IL-10-/- mice & 6 weeks & $\begin{array}{l}1.5 \mathrm{mg} / \mathrm{kg} / \mathrm{d} \\
18 \text { weeks }\end{array}$ & Mouse FI & $\begin{array}{l}\text { Decreases levels of myostatin } \\
\text { which may prevent muscle mass } \\
\text { loss and frailty (23) }\end{array}$ \\
\hline $\begin{array}{l}\text { Dasatinib and } \\
\text { quercetin }\end{array}$ & $\begin{array}{l}\text { Senolytic } \\
\text { drugs }\end{array}$ & Male, C57BL/6J mice & $\begin{array}{l}\text { (1) } 20 \text { months } \\
\text { (2) } 24-27 \text { months }\end{array}$ & $\begin{array}{l}\text { A } \\
\text { combination } \\
\text { of dasatinib (5 } \\
\text { mg/kg) and } \\
\text { quercetin (50 } \\
\mathrm{mg} / \mathrm{kg}) \\
\text { (1) } 4 \text { months } \\
\text { (2) Natural death }\end{array}$ & Physical function & $\begin{array}{l}\text { Alleviates symptoms of frailty and } \\
\text { extends healthspan (78) }\end{array}$ \\
\hline Nicotinamide & $\begin{array}{l}\text { NAD+ } \\
\text { precursor }\end{array}$ & Male, C57BL/6J mice & 56 weeks & $\begin{array}{l}0.5 \text { and } 1.0 \\
\mathrm{~g} / \mathrm{kg}, 62 \\
\text { weeks }\end{array}$ & - & $\begin{array}{l}\text { Improves healthspan but does } \\
\text { not extend lifespan (79) }\end{array}$ \\
\hline
\end{tabular}

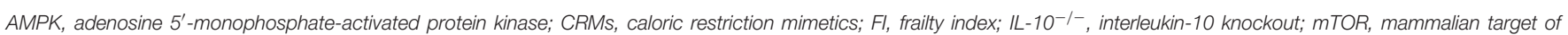
rapamycin; NAD, nicotinamide adenine dinucleotide; SD, Sprague-Dawley; SIRT1, silent mating-type information regulation 2 homolog 1.

practiced for 5 months may not affect cognition in sedentary older adults with obesity (92). Thus, further investigations are required to determine lifestyle interventions suitable for older adults and those with frailty or sarcopenia.

\section{POTENTIAL RISKS ASSOCIATED WITH CR}

Malnutrition is common in older adults and increases the risk of frailty, sarcopenia, comorbidities, and premature death. CR may delay the onset of frailty and sarcopenia, potentially helping to improve the quality of life of older people. However, extreme CR may lead to adverse events, such as sarcopenia, osteoporosis, and immune deficiencies (93). Aged rats with 3 months of CR had poorer performance and frailty scores than their counterparts (19). This finding was consistent with that of another study showing that $40 \% \mathrm{CR}$ initiated in mice aged 22-24 months increased mortality rates in male C57BL/6, DBA/2, and B6D2F1 mice (94). Further, CR accelerated the loss of gray matter but preserved the white matter in the brain of aged mouse lemurs; neither effect altered the cognitive performance (20). While chronic food restriction may impair spatial recognition memory in developing mice (an effect mediated by the extent of food restriction and individual tolerability), acute food restriction exerts negative effects on locomotor activity in mice (95). The relationships between $\mathrm{CR}$, genetics, sex, animal strains, as well as regimen duration and extent, are complex. Future studies are required to elucidate the suitable timing, duration, and extent of CR that may help prevent the onset of frailty in older adults.

\section{CONCLUSION}

Caloric restriction has shown some benefits in both animal and human studies; however, the factors that determine the impact of CR remain unclear (19). Rodent and non-human primate models of CR are associated with the limitations that may affect study designs. The impact of CR on aging may be mediated by dietary composition, sex, age at onset, feeding regimens, and genetics (96). There is no standard for CR regimens (e.g., timing of initiation and duration, or caloric intake values). In addition, the evidence on the association between CR and frailty in the clinical setting is insufficient. Moreover, the underlying mechanisms are unclear. Consequently, further studies are required to elucidate the caloric intake and nutrient composition optimal for healthy aging in humans.

\section{AUTHOR CONTRIBUTIONS}

PL, YL, and LM contributed to the organization of the manuscript. PL drafted the manuscript and composed the outline. YL and LM reviewed and approved the submitted version. All the authors agree to be accountable for the content of the study.

\section{FUNDING}

This study was funded by the Beijing Natural Science Foundation (7202059) and Beijing Municipal Health Commission (Jing2019-2). 


\section{REFERENCES}

1. Fried LP, Tangen CM, Walston J, Newman AB, Hirsch C, Gottdiener J, et al. Frailty in older adults: evidence for a phenotype. J Gerontol A Biol Sci Med Sci. (2001) 56:M146-56. doi: 10.1093/gerona/56.3.M146

2. Clegg A, Young J, Iliffe S, Rikkert MO, Rockwood K. Frailty in elderly people. Lancet. (2013) 381:752-62. doi: 10.1016/S0140-6736(12)62167-9

3. Collard RM, Boter H, Schoevers RA, Voshaar RCO. Prevalence of frailty in community-dwelling older persons: a systematic review. J Am Geriatr Soc. (2012) 60:1487-92. doi: 10.1111/j.1532-5415.2012.04054.x

4. Mitnitski AB, Mogilner AJ, Rockwood K. Accumulation of deficits as a proxy measure of aging. Sci World J. (2001) 1:323-36. doi: 10.1100/tsw.2001.58

5. Whitehead JC, Hildebrand BA, Sun M, Rockwood MR, Rose RA, Rockwood $\mathrm{K}$, et al. A clinical frailty index in aging mice: comparisons with frailty index data in humans. J Gerontol A Biol Sci Med Sci. (2014) 69:62132. doi: 10.1093/gerona/glt136

6. Yorke A, Kane AE, Hancock Friesen CL, Howlett SE, O’Blenes S. Development of a rat clinical frailty index. J Gerontol A Biol Sci Med Sci. (2017) 72:897-903. doi: 10.1093/gerona/glw339

7. Deepa SS, Bhaskaran S, Espinoza S, Brooks SV, McArdle A, Jackson MJ, et al. A new mouse model of frailty: the $\mathrm{Cu} / \mathrm{Zn}$ superoxide dismutase knockout mouse. Geroscience. (2017) 39:187-98. doi: 10.1007/s11357-017-9975-9

8. Walston J, Fedarko N, Yang H, Leng S, Beamer B, Espinoza S, et al. The physical and biological characterization of a frail mouse model. J Gerontol A Biol Sci Med Sci. (2008) 63:391-8. doi: 10.1093/gerona/63.4.391

9. Kojima G, Iliffe S, Jivraj S, Walters K. Association between frailty and quality of life among community-dwelling older people: a systematic review and meta-analysis. J Epidemiol Community Health. (2016) 70:71621. doi: 10.1136/jech-2015-206717

10. Schafer MJ, White TA, Evans G, Tonne JM, Verzosa GC, Stout MB, et al. Exercise prevents diet-induced cellular senescence in adipose tissue. Diabetes. (2016) 65:1606-15. doi: 10.2337/db15-0291

11. Most J, Tosti V, Redman LM, Fontana L. Calorie restriction in humans: an update. Ageing Res Rev. (2017) 39:36-45. doi: 10.1016/j.arr.2016.08.005

12. Lopez-Lluch $G$, Navas P. Calorie restriction as an intervention in ageing. $J$ Physiol. (2016) 594:2043-60. doi: 10.1113/JP270543

13. Caristia S, Vito MD, Sarro A, Leone A, Pecere A, Zibetti A, et al. Is caloric restriction associated with better healthy aging outcomes? A systematic review and meta-analysis of randomized controlled trials. Nutrients. (2020) 12:2290. doi: 10.3390/nu12082290

14. Perry CA, Van Guilder GP, Hossain M, Kauffman A. Cardiometabolic changes in response to a calorie-restricted DASH diet in obese older adults. Front Nutr. (2021) 8:647847. doi: 10.3389/fnut.2021.647847

15. Palliyaguru DL, Moats JM, Di Germanio C, Bernier M, de Cabo R. Frailty index as a biomarker of lifespan and healthspan: focus on pharmacological interventions. Mech Ageing Dev. (2019) 180:4248. doi: 10.1016/j.mad.2019.03.005

16. Arum O, Rasche ZA, Rickman DJ, Bartke A. Prevention of neuromusculoskeletal frailty in slow-aging ames dwarf mice: longitudinal investigation of interaction of longevity genes and caloric restriction. PLoS ONE. (2013) 8:e72255. doi: 10.1371/journal.pone.00 72255

17. Arum O, Rickman DJ, Kopchick JJ, Bartke A. The slow-aging growth hormone receptor/binding protein gene-disrupted (GHR-KO) mouse is protected from aging-resultant neuromusculoskeletal frailty. Age. (2014) 36:117-27. doi: 10.1007/s11357-013-9551-x

18. Kane AE, Hilmer SN, Boyer D, Gavin K, Nines D, Howlett SE, et al. Impact of longevity interventions on a validated mouse clinical frailty index. J Gerontol A Biol Sci Med Sci. (2016) 71:333-9. doi: 10.1093/gerona/glu315

19. Todorovic ST, Smiljanic KR, Ruzdijic SD, Djordjevic ANM, Kanazir SD. Effects of different dietary protocols on general activity and frailty of male wistar rats during aging. J Gerontol Ser A. (2018) 73:103644. doi: 10.1093/gerona/gly015

20. Pifferi F, Terrien J, Marchal J, Dal-Pan A, Djelti F, Hardy I, et al. Caloric restriction increases lifespan but affects brain integrity in grey mouse lemur primates. Communic Biol. (2018) 1:30. doi: 10.1038/s42003-018-0024-8
21. Colman RJ, Beasley TM, Kemnitz JW, Johnson SC, Weindruch R, Anderson $\mathrm{RM}$. Caloric restriction reduces age-related and all-cause mortality in rhesus monkeys. Nat Commun. (2014) 5:3557. doi: 10.1038/ncomms4557

22. Yamada Y, Kemnitz JW, Weindruch R, Anderson RM, Schoeller DA, Colman RJ. Caloric restriction and healthy life span: frail phenotype of nonhuman primates in the wisconsin national primate research center caloric restriction study. J Gerontol A Biol Sci Med Sci. (2018) 73:2738. doi: 10.1093/gerona/glx059

23. Pérez-Martínez L, Romero L, Muñoz-Galván S, Verdugo-Sivianes EM, Rubio-Mediavilla S, Oteo JA, et al. Implications of maraviroc and/or rapamycin in a mouse model of fragility. Aging. (2020) 12:856582. doi: 10.18632/aging.103167

24. Jang YC, Liu Y, Hayworth CR, Bhattacharya A, Lustgarten MS, Muller FL, et al. Dietary restriction attenuates age-associated muscle atrophy by lowering oxidative stress in mice even in complete absence of CuZnSOD. Aging Cell. (2012) 11:770-82. doi: 10.1111/j.1474-9726.2012.00843.x

25. Zhang Y, Unnikrishnan A, Deepa SS, Liu Y, Li Y, Ikeno Y, et al. A new role for oxidative stress in aging: the accelerated aging phenotype in Sod1/- mice is correlated to increased cellular senescence. Redox Biol. (2017) 11:30-7. doi: 10.1016/j.redox.2016.10.014

26. Heilbronn LK, Jonge Ld, Frisard MI, DeLany JP, Larson-Meyer DE, Rood J, et al. Effect of 6-month calorie restriction on biomarkers of longevity, metabolic adaptation, and oxidative stress in overweight individuals: a randomized controlled trial. JAMA. (2006) 295:1539-48. doi: 10.1001/jama.295.13.1539

27. Kraus WE, Bhapkar M, Huffman KM, Pieper CF, Krupa Das S, Redman LM, et al. 2 years of calorie restriction and cardiometabolic risk (CALERIE): exploratory outcomes of a multicentre, phase 2, randomised controlled trial. Lancet Diabetes Endocrinol. (2019) 7:673-83. doi: 10.1016/S2213-8587(19)30151-2

28. Grigolon RB, Brietzke E, Trevizol AP, McIntyre RS, Mansur RB. Caloric restriction, resting metabolic rate and cognitive performance in non-obese adults: a post-hoc analysis from CALERIE study. J Psychiatr Res. (2020) 128:16-22. doi: 10.1016/j.jpsychires.2020.05.018

29. Il'yasova D, Fontana L, Bhapkar M, Pieper CF, Spasojevic I, Redman LM, et al. Effects of 2 years of caloric restriction on oxidative status assessed by urinary F2-isoprostanes: the CALERIE 2 randomized clinical trial. Aging Cell. (2018) 17:e12719. doi: 10.1111/acel.12719

30. Sakuma K, Yamaguchi A. Recent advances in pharmacological, hormonal, and nutritional intervention for sarcopenia. Pflugers Arch. (2018) 470:44960. doi: 10.1007/s00424-017-2077-9

31. Anton SD, Lee SA, Donahoo WT, McLaren C, Manini T, Leeuwenburgh C, et al. The effects of time restricted feeding on overweight, older adults: a pilot study. Nutrients. (2019) 11:1500. doi: 10.3390/nu11071500

32. Hord JM, Botchlett R, Lawler JM. Age-related alterations in the sarcolemmal environment are attenuated by lifelong caloric restriction and voluntary exercise. Exp Gerontol. (2016) 83:148-57. doi: 10.1016/j.exger.2016.08.006

33. Kvedaras M, Minderis P, Krusnauskas R, Ratkevicius A. Effects of ten-week $30 \%$ caloric restriction on metabolic health and skeletal muscles of adult and old C57BL/6J mice. Mech Ageing Dev. (2020) 190:111320. doi: 10.1016/j.mad.2020.111320

34. McKiernan SH, Colman RJ, Lopez M, Beasley TM, Aiken JM, Anderson RM, et al. Caloric restriction delays aging-induced cellular phenotypes in rhesus monkey skeletal muscle. Exp Gerontol. (2011) 46:23-9. doi: 10.1016/j.exger.2010.09.011

35. Colman RJ, Beasley TM, Allison DB, Weindruch R. Attenuation of sarcopenia by dietary restriction in rhesus monkeys. J Gerontol A Biol Sci Med Sci. (2008) 63:556-9. doi: 10.1093/gerona/63.6.556

36. Boldrin L, Ross JA, Whitmore C, Doreste B, Beaver C, Eddaoudi A, et al. The effect of calorie restriction on mouse skeletal muscle is sex, strain and time-dependent. Sci Rep. (2017) 7:5160. doi: 10.1038/s41598-017-04896-y

37. Imai S. SIRT1 and caloric restriction: an insight into possible trade-offs between robustness and frailty. Curr Opin Clin Nutr Metab Care. (2009) 12:350-6. doi: 10.1097/MCO.0b013e32832c932d

38. Kubben N, Misteli T. Shared molecular and cellular mechanisms of premature ageing and ageing-associated diseases. Nat Rev Mol Cell Biol. (2017) 18:595609. doi: $10.1038 / \mathrm{nrm} .2017 .68$ 
39. Ma L, Dong W, Wang R, Li Y, Xu B, Zhang J, et al. Effect of caloric restriction on the SIRT1/mTOR signaling pathways in senile mice. Brain Res Bull. (2015) 116:67-72. doi: 10.1016/j.brainresbull.2015.06.004

40. Kumar R, Mohan N, Upadhyay AD, Singh AP, Sahu V, Dwivedi S, et al. Identification of serum sirtuins as novel noninvasive protein markers for frailty. Aging Cell. (2014) 13:975-80. doi: 10.1111/acel.12260

41. Razi S, Cogger VC, Kennerson M, Benson VL, McMahon AC, Blyth FM, et al. SIRT1 polymorphisms and serum-induced SIRT1 protein expression in aging and frailty: the CHAMP study. J Gerontol A Biol Sci Med Sci. (2017) 72:870-6. doi: 10.1093/gerona/glx018

42. Ma L, Niu H, Sha G, Zhang Y, Liu P, Li Y. Serum SIRT1 is associated with frailty and adipokines in older adults. J Nutr Health Aging. (2018) 23:246-50. doi: 10.1007/s12603-018-1149-7

43. Couteur DGL, Benson VL, McMahon AC, Blyth F, Handelsman DJ, Seibel MJ, et al. Determinants of serum-induced SIRT1 expression in older men: the CHAMP study. J Gerontol A Biol Sci Med Sci. (2011) 66:38. doi: $10.1093 /$ gerona/glq158

44. Tchkonia T, Zhu Y, Deursen Jv, Campisi J, Kirkland JL. Cellular senescence and the senescent secretory phenotype: therapeutic opportunities. J Clin Invest. (2013) 123:966-72. doi: 10.1172/JCI64098

45. Kim DH, Bang E, Jung HJ, Noh SG, Yu BP, Choi YJ, et al. Anti-aging effects of Calorie Restriction (CR) and CR mimetics based on the senoinflammation concept. Nutrients. (2020) 12:422. doi: 10.3390/nu12020422

46. Kalani R, Judge S, Carter C, Pahor M, Leeuwenburgh C. Effects of caloric restriction and exercise on age-related, chronic inflammation assessed by C-reactive protein and interleukin-6. J Gerontol A Biol Sci Med Sci. (2006) 61:211-7. doi: 10.1093/gerona/61.3.211

47. Chen Y, Liu S, Leng SX. Chronic Low-grade Inflammatory Phenotype (CLIP) and senescent immune dysregulation. Clin Ther. (2019) 41:4009. doi: 10.1016/j.clinthera.2019.02.001

48. Chung HY, Lee EK, Choi YJ, Kim JM, Kim DH, Zou Y, et al. Molecular inflammation as an underlying mechanism of the aging process and age-related diseases. J Dent Res. (2011) 90:830-40. doi: $10.1177 / 0022034510387794$

49. Min S-W, Sohn PD, Cho S-H, Swanson RA, Gan L. Sirtuins in neurodegenerative diseases: an update on potential mechanisms. Front Aging Neurosci. (2013) 5:53. doi: 10.3389/fnagi.2013.00053

50. White MJ, Beaver CM, Goodier MR, Bottomley C, Nielsen CM, Wolf A-SFM, et al. Calorie restriction attenuates terminal differentiation of immune cells. Front Immunol. (2016) 7:667. doi: 10.3389/fimmu.2016.00667

51. Larrick JW, Larrick JW, Mendelsohn AR. Contribution of ferroptosis to aging and frailty. Rejuvenat Res. (2020) 23:434-8. doi: 10.1089/rej.20 20.2390

52. García-Matas S, Paul RK, Molina-Martínez P, Palacios H, Gutierrez VM, Corpas $\mathrm{R}$, et al. In vitro caloric restriction induces protective genes and functional rejuvenation in senescent SAMP8 astrocytes. Aging Cell. (2015) 14:334-44. doi: 10.1111/acel.12259

53. Yu D, Tomasiewicz JL, Yang SE, Miller BR, Wakai MH, Sherman DS, et al. Calorie-Restriction-induced insulin sensitivity is mediated by adipose mTORC2 and not required for lifespan extension. Cell Rep. (2019) 29:23648.e3. doi: 10.1016/j.celrep.2019.08.084

54. Marzetti E, Privitera G, Simili V, Wohlgemuth SE, Aulisa L, Pahor M, et al. Multiple pathways to the same end: mechanisms of myonuclear apoptosis in sarcopenia of aging. Sci World J. (2010) 10:340-9. doi: 10.1100/tsw.2010.27

55. Marzetti E, Calvani R, Bernabei R, Leeuwenburgh C. Apoptosis in skeletal myocytes: a potential target for interventions against sarcopenia and physical frailty - a mini-review. Gerontology. (2012) 58:99-106. doi: 10.1159/000330064

56. Wohlgemuth SE, Seo AY, Marzetti E, Lees HA, Leeuwenburgh C. Skeletal muscle autophagy and apoptosis during aging: effects of calorie restriction and life-long exercise. Exp Gerontol. (2010) 45:138-48. doi: 10.1016/j.exger.2009.11.002

57. Kim J-H, Lee Y, Kwak H-B, Lawler JM. Lifelong wheel running exercise and mild caloric restriction attenuate nuclear EndoG in the aging plantaris muscle. Exp Gerontol. (2015) 69:122-8. doi: 10.1016/j.exger.2015.06.007

58. Sandri M, Barberi L, Bijlsma AY, Blaauw B, Dyar KA, Milan G, et al. Signalling pathways regulating muscle mass in ageing skeletal muscle: the role of the IGF1-Akt-mTOR-FoxO pathway. Biogerontology. (2013) 14:30323. doi: $10.1007 / \mathrm{s} 10522-013-9432-9$
59. Gouspillou G, Picard M, Godin R, Burelle Y, Hepple RT. Role of peroxisome proliferator-activated receptor gamma coactivator 1-alpha (PGC-1 $\alpha)$ in denervation-induced atrophy in aged muscle: facts and hypotheses. Longevity Healthspan. (2013) 2:13. doi: 10.1186/2046-2395-2-13

60. Rhoads TW, Clark JP, Gustafson GE, Miller KN, Conklin MW, DeMuth $\mathrm{TM}$, et al. Molecular and functional networks linked to sarcopenia prevention by caloric restriction in rhesus monkeys. Cell Syst. (2020) 10:15668.e5. doi: 10.1016/j.cels.2019.12.002

61. Xie W-Q, Xiao W-F, Tang K, Wu Y-X, Hu P-W, Li Y-S, et al. Caloric restriction: implications for sarcopenia and potential mechanisms. Aging. (2020) 12:24441-52. doi: 10.18632/aging.103987

62. Tussing-Humphreys L, Lamar M, Blumenthal JA, Babyak M, Fantuzzi G, Blumstein L, et al. Building research in diet and cognition: the BRIDGE randomized controlled trial. Contemp Clin Trials. (2017) 59:8797. doi: 10.1016/j.cct.2017.06.003

63. Capurso C, Bellanti F, Buglio AL, Vendemiale G. The Mediterranean Diet slows down the progression of aging and helps to prevent the onset of frailty: a narrative review. Nutrients. (2019) 12:35. doi: 10.3390/nu12010035

64. Dent E, Morley JE, Cruz-Jentoft AJ, Woodhouse L, Rodríguez-Mañas L, Fried LP, et al. Physical frailty: ICFSR International Clinical Practice Guidelines for Identification and Management. J Nutr Health Aging. (2019) 23:77187. doi: $10.1007 / \mathrm{s} 12603-019-1273-\mathrm{z}$

65. Mattson MP, Longo VD, Harvie M. Impact of intermittent fasting on health and disease processes. Ageing Res Rev. (2017) 39:46-58. doi: 10.1016/j.arr.2016.10.005

66. Harris L, Hamilton S, Azevedo LB, Olajide J, De Brun C, Waller G, et al. Intermittent fasting interventions for treatment of overweight and obesity in adults: a systematic review and meta-analysis. JBI Database Syst Rev Implement Rep. (2018) 16:507-47. doi: 10.11124/JBISRIR-2016-003248

67. Hoddy KK, Marlatt KL, Cetinkaya H, Ravussin E. Intermittent fasting and metabolic health: from religious fast to time-restricted feeding. Obesity. (2020) 28(Suppl. 1):S29-37. doi: 10.1002/oby.22829

68. Harris L, McGarty A, Hutchison L, Ells L, Hankey C. Short-term intermittent energy restriction interventions for weight management: a systematic review and meta-analysis. Obes Rev. (2018) 19:1-13. doi: 10.1111/obr.12593

69. Cienfuegos S, Gabel K, Kalam F, Ezpeleta M, Wiseman E, Pavlou V, et al. Effects of 4- and 6-h time-restricted feeding on weight and cardiometabolic health: a randomized controlled trial in adults with obesity. Cell Metab. (2020) 32:366-78.e3. doi: 10.1016/j.cmet.2020.06.018

70. Henderson YO, Bithi N, Link C, Yang J, Schugar R, Llarena N, et al. Latelife intermittent fasting decreases aging-related frailty and increases renal hydrogen sulfide production in a sexually dimorphic manner. Geroscience. (2021). doi: 10.1007/s11357-021-00330-4. [Epub ahead of print].

71. Madeo F, Pietrocola F, Eisenberg T, Kroemer G. Caloric restriction mimetics: towards a molecular definition. Nat Rev Drug Discov. (2014) 13:72740. doi: $10.1038 / \mathrm{nrd} 4391$

72. Madeo F, Carmona-Gutierrez D, Hofer SJ, Kroemer G. Caloric restriction mimetics against age-associated disease: targets, mechanisms, therapeutic potential. Cell Metab. (2019) 29:592-610. doi: 10.1016/j.cmet.2019.01.018

73. Liao Z-Y, Chen J-L, Xiao M-H, Sun Y, Zhao Y-X, Pu D, et al. The effect of exercise, resveratrol or their combination on Sarcopenia in aged rats via regulation of AMPK/Sirt1 pathway. Exp Gerontol. (2017) 98:17783. doi: 10.1016/j.exger.2017.08.032

74. Mitchell SJ, Martin-Montalvo A, Mercken EM, Palacios HH, Ward TM, Abulwerdi G, et al. The SIRT1 activator SRT1720 extends lifespan and improves health of mice fed a standard diet. Cell Rep. (2014) 6:83643. doi: 10.1016/j.celrep.2014.01.031

75. Wang C-P, Lorenzo C, Espinoza SE. Frailty attenuates the impact of metformin on reducing mortality in older adults with type 2 diabetes. $J$ Endocrinol Diabetes Obesity. (2014) 2:1031.

76. Baskaran D, Aparicio-Ugarriza R, Ferri-Guerra J, Milyani R, Florez H, Ruiz JG. Is There an Association Between Metformin Exposure and Frailty? Gerontol Geriatr Med (2020) 6:2333721420924956. doi: 10.1177/2333721420924956

77. Singh M, Jensen MD, Lerman A, Kushwaha S, Rihal CS, Gersh BJ, et al. Effect of low-dose rapamycin on senescence markers and physical functioning in older adults with coronary artery disease: results of a pilot study. J Frailty Aging. (2016) 5:204-7. doi: 10.14283/jfa.2016.112 
78. Xu M, Pirtskhalava T, Farr JN, Weigand BM, Palmer AK, Weivoda MM, et al. Senolytics improve physical function and increase lifespan in old age. Nat Med. (2018) 24:1246-56. doi: 10.1038/s41591-018-0092-9

79. Mitchell SJ, Bernier M, Aon MA, Cortassa S, Kim EY, Fang EF, et al. Nicotinamide improves aspects of healthspan, but not lifespan, in mice. Cell Metab. (2018) 27:667-76.e4. doi: 10.1016/j.cmet.2018.02.001

80. Verspoor E, Voortman T, van Rooij FJA, Rivadeneira F, Franco OH, Kiefte-de Jong JC, et al. Macronutrient intake and frailty: the Rotterdam Study. Eur J Nutr. (2020) 59:2919-28. doi: 10.1007/s00394-019-02131-0

81. Couteur DGL, Solon-Biet S, Cogger VC, Mitchell SJ, Senior A, Cabo Rd, et al. The impact of low-protein high-carbohydrate diets on aging and lifespan. Cell Mol Life Sci. (2016) 73:1237-52. doi: 10.1007/s00018-015-2120-y

82. Speakman JR, Mitchell SE, Mazidi M. Calories or protein? The effect of dietary restriction on lifespan in rodents is explained by calories alone. Exp Gerontol. (2016) 86:28-38. doi: 10.1016/j.exger.2016.03.011

83. Alvers AL, Fishwick LK, Wood MS, Hu D, Chung HS, Dunn WA, et al. Autophagy and amino acid homeostasis are required for chronological longevity in Saccharomyces cerevisiae. Aging cell. (2009) 8:353-69. doi: 10.1111/j.1474-9726.2009.00469.x

84. D'Antona G, Ragni M, Cardile A, Tedesco L, Dossena M, Bruttini F, et al. Branched-chain amino acid supplementation promotes survival and supports cardiac and skeletal muscle mitochondrial biogenesis in middle-aged mice. Cell Metab. (2010) 12:362-72. doi: 10.1016/j.cmet.2010.08.016

85. Schoufour JD, Overdevest E, Weijs PJM, Tieland M. Dietary protein, exercise, frailty domains. Nutrients. (2019) 11:2399. doi: 10.3390/nu11102399

86. Valerio A, D’Antona G, Nisoli E. Branched-chain amino acids, mitochondrial biogenesis, and healthspan: an evolutionary perspective. Aging. (2011) 3:46478. doi: 10.18632/aging.100322

87. Richardson NE, Konon EN, Schuster HS, Mitchell AT, Boyle C, Rodgers $\mathrm{AC}$, et al. Lifelong restriction of dietary branched-chain amino acids has sex-specific benefits for frailty and lifespan in mice. Nat Aging. (2021) 1:7386. doi: 10.1038/s43587-020-00006-2

88. de Labra C, Guimaraes-Pinheiro C, Maseda A, Lorenzo T, Millán-Calenti JC. Effects of physical exercise interventions in frail older adults: a systematic review of randomized controlled trials. BMC Geriatr. (2015) 15:154. doi: 10.1186/s12877-015-0155-4

89. Sardeli AV, Komatsu TR, Mori MA, Gaspari AF, Chacon-Mikahil MPT. Resistance training prevents muscle loss induced by caloric restriction in obese elderly individuals: a systematic review and meta-analysis. Nutrients. (2018) 10:423. doi: 10.3390/nu10040423
90. Simpson FR, Pajewski NM, Nicklas B, Kritchevsky S, Bertoni A, Ingram $\mathrm{F}$, et al. Impact of multidomain lifestyle intervention on frailty through the lens of deficit accumulation in adults with type 2 diabetes mellitus. J Gerontol A Biol Sci Med Sci. (2020) 75:1921-7. doi: 10.1093/gerona/g lz197

91. Gomez-Cabrera MC. Exercise as a calorie restriction mimetic. Implications for the treatment of age associated frailty. Free Radical Biol Med. (2018) 120:S16. doi: 10.1016/j.freeradbiomed.2018.04.068

92. Hugenschmidt CE, Leng X, Lyles M, Michael L, Dougherty A, Babcock P, et al. Cognitive effects of adding caloric restriction to aerobic exercise training in older adults with obesity. Obesity. (2019) 27:1266-74. doi: 10.1002/oby.22525

93. Fontana L, Partridge L, Longo VD. Extending healthy life span-from yeast to humans. Science. (2010) 328:321-6. doi: 10.1126/science.1172539

94. Forster MJ, Morris P, Sohal RS. Genotype and age influence the effect of caloric intake on mortality in mice. FASEB J. (2003) 17:6902. doi: 10.1096/fj.02-0533fje

95. Fu Y, Chen Y, Li L, Wang Y, Kong X, Wang J. Food restriction affects Y-maze spatial recognition memory in developing mice. Int J Dev Neurosci. (2017) 60:8-15. doi: 10.1016/j.ijdevneu.2017.03.010

96. Vaughan KL, Kaiser T, Peaden R, Anson RM, de Cabo R, Mattison JA. Caloric restriction study design limitations in rodent and nonhuman primate studies. J Gerontol A Biol Sci Med Sci. (2017) 73:48-53. doi: 10.1093/gerona/glx088

Conflict of Interest: The authors declare that the research was conducted in the absence of any commercial or financial relationships that could be construed as a potential conflict of interest.

Publisher's Note: All claims expressed in this article are solely those of the authors and do not necessarily represent those of their affiliated organizations, or those of the publisher, the editors and the reviewers. Any product that may be evaluated in this article, or claim that may be made by its manufacturer, is not guaranteed or endorsed by the publisher.

Copyright (C) $2021 \mathrm{Liu}, \mathrm{Li}$ and Ma. This is an open-access article distributed under the terms of the Creative Commons Attribution License (CC BY). The use, distribution or reproduction in other forums is permitted, provided the original author(s) and the copyright owner(s) are credited and that the original publication in this journal is cited, in accordance with accepted academic practice. No use, distribution or reproduction is permitted which does not comply with these terms. 